\title{
The optical properties of different materials used for thermo-optical switches
}

\author{
Michaela Holá ${ }^{1}$, Martin Králik ${ }^{1}$, \\ Jarmila Müllerová ${ }^{1}$, L’ubomír Scholtz ${ }^{2}$
}

\begin{abstract}
With growing demands of internet protocol services for transmission capacity and speed, the solution for future high speed optical networks is optical burst switching that is a technology for transmitting large amounts of data bursts through a transparent optical switching network the optical switches in optical burst switching networks play important role in the resource reservation and are very important to ensure reliability and flexibility of the network. This paper is focused on the very important components of Optical Burst Switching networks, $i e_{o}$ ptical switches, specifically thermo-optical switches. In this paper are presented the simulation analysis of performance evaluation of thermo-optical switches executed in the model of Optical Burst Switching network and simulation study of investigation of influence of roughness and layer thickness on the optical properties (spectral reflectance, transmittance) of selected materials $\left(\mathrm{SiO}_{2}, \mathrm{Ta}_{2} \mathrm{O}_{5}, \mathrm{Al}_{2} \mathrm{O}_{3}\right)$ for thermooptical switches.

Keywords: optical burst switching, thermooptical switches, thin films, modified fresnel coefficients, transfer matrix theory, spectral reflectance, transmittance
\end{abstract}

\section{Introduction}

At the present there is an increasing demand for transmission capacity of optical transmission systems and networks due to a very rapid data traffic growth over the Internet, and it is predicted that this growing trend will continue. With growing demands of IP services for transmission capacity and speed, Optical Burst Switching (OBS) networks present the solution for future high-speed WDM optical networks. The optical switches are very important components of OBS networks and currently, several switching technologies are available. Very attractive candidates to realize high-speed optical switching are optical switches based on thermo-optic effect. Regarding materials for thermo-optical switches, it is well known that a large number of materials have been investigated. The properties of materials, ie . mechanical, thermal and optical, directly influence the performance switches. From the mentioned properties of materials for thermo-optical switches, optical properties are very important, due to their significant influence on transmitted signal power [1$6]$.

In order to investigate the optical properties of the materials for thermo-optical switches, were performed simulations that aim to point out the sensitivity of individual materials to parameters such as thickness and surface roughness. For this purpose, $\mathrm{SiO}_{2}, \mathrm{Ta}_{2} \mathrm{O}_{5}$, and $\mathrm{Al}_{2} \mathrm{O}_{3}$ were selected. In the first step of optical properties simu- lations, were mainly focused on investigating the effect of increasing the thickness of the thin layer of material on its transmittance. In the second step, were investigated the effect of surface roughness on the transmittance of the presented materials.

\section{Optical burst switching}

To successfully transmit bursts, resource reservation schemes have to be implemented to allocate resources and configure optical switches for that burst at each node. Therefore, the optical switches play an important role in resources reservation, provide the optical path and improve the optical network reliability [1-6].

Currently, several switching technologies are available, eg switches based on electro-optic effect, acousto-optic effect, thermo-optic effect, magneto-optic effect, nonlinear optic effect, micro-electro-mechanical system (MEMS) principle, semiconductor optical amplifier (SOA) principle, liquid crystal principle, photonic crystal principle, holographic principle, quantum well/dots, etc. Optical switches should meet the following requirements [7-11]: high switching speed (switching time must be shorter as required for burst transmission), dimension of switching structure, low insertion losses or sufficient amplification, low crosstalk between channels and simplicity and easy integrability.

\footnotetext{
${ }^{1}$ Institute of Aurel Stodola, Faculty of Electrical Engineering and Information Technology, University of Žilina, ul. kpt. J. Nálepku 1390, 03101 Liptovský Mikuláš Slovakia, michaela.hola@feit.uniza.sk, ${ }^{2}$ Department of Electronics, Armed Forces Academy of General Milan Rastislav Štefánik, Demänová 393, 03101 Liptovský Mikuláš Slovakia
}

https://doi.org/10.2478/jee-2021-0025, Print (till 2015) ISSN 1335-3632, On-line ISSN 1339-309X (C) This is an open access article licensed under the Creative Commons Attribution-NonCommercial-NoDerivs License (http: //creativecommons.org/licenses/by-nc-nd/3.0/). 


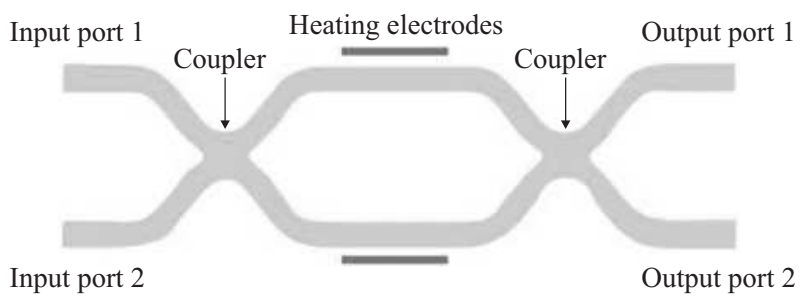

Fig. 1. Scheme of $2 \times 2$ interferometric switch

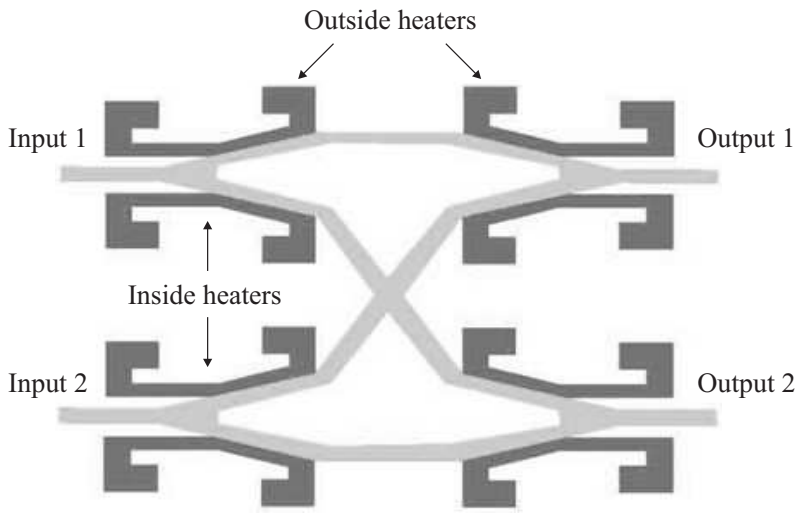

Fig. 2. Scheme of $2 \times 2$ digital optical switch

\section{Thermo-optical switches}

The operation of these optical switches is based on the thermo-optic effect (the thermo-optic effect is present in all materials and is described by the thermo-optic coefficient). Thermo-optical switches are very desirable due to their small size, large scalability and potentiality for integration with waveguide DWDM multiplexers and demultiplexers. They have an important role in optical telecommunication applications, such as optical crossconnection (OXC), protection switching and switch arrays for optical add-drop multiplexing (OADM). A number of configurations of thermo-optical switch have been developed. They include interferometric devices such as a directional coupler and MachZehnder configurations, digital optical switches based on modal evolution in the conventional Y-junction branch and based on total internal reflection (TIR), and thermo-optical switches based on micro-optoelectro-mechanical system (MOEMS) technologies [7-11].

In Fig. 1-2 are shown two examples of configurations of thermo-optical switch, $i e$. interferometric and digital optical switch. The interferometric switch is usually based on MachZehnder interferometers. As shown in Fig. 1, the switch consists of a $3-\mathrm{dB}$ coupler that splits the signal into two beams, which then travel through two distinct arms of same length, and of a second 3-dB coupler, which merges and finally splits the signal again. Heating one arm of the interferometer causes its refractive index to change. Consequently, a variation of the optical path of that arm is experienced. It is thus possible to vary the phase difference between the light beams, by heating one of the arms of the interferometer. Hence, as interference is constructive or destructive, the power on alternate outputs is minimized or maximized. The output port is thus selected [7].

Digital optical switch is integrated optical device generally made of silica on silicon. As shown in Fig. 2, the switch is composed of two interacting waveguide arms through which light propagates. The phase error between the beams at the two arms determines the output port. Heating one of the arms changes its refractive index, and the light is transmitted down one path rather than the other. An electrode through control electronics provides the heating [7].

\section{Materials of thermo-optical switches and simulation of their optical properties}

Regarding materials, it is well known that a large number of materials have been investigated. In order to be selected for thermo-optical switch fabrication, a material has to satisfy the following set of requirements [10-11] low optical losses (no more than $0.1 \mathrm{~dB} / \mathrm{cm}$ ) in the communication spectral windows around 850, 1300 or 1550 $\mathrm{nm}$, low wavelength dispersion, low birefringence, low polarization-dependent losses, thermally stable mechanical properties, resistance to humidity, good mechanical properties such as flexibility and toughness, low cost and high thermo-optic coefficient.

In production of thermo-optical switches, the main materials are Benzocyclobutene (BCB), Bisphenol Aaldehyde (BPA), Fluoroacrylate (FA), Fluorinated poly (arylene ether sulphide) (FPAE), Poly (methyl methacrylate) (PMMA), Polyimide (PI), Polyurethane (PUR), 
Table 1. Coefficients of dispersion model of $\mathrm{SiO}_{2}$ [16]

\begin{tabular}{lcccc}
$A$ & $B$ & $C$ & $D$ & $F$ \\
\hline 1.286 & 1.0704 & 0.010 & 1.102 & 100 \\
\hline
\end{tabular}

silica $\left(\mathrm{SiO}_{2}\right)$, silicon, silicon nanocrystals, III-V semiconductors (GaAs, AlGaAs, InP, etc), Lithium niobite (LiNbO3), Tantalum pentoxide $\left(\mathrm{Ta}_{2} \mathrm{O}_{5}\right)$ and Aluminium oxide $\left(\mathrm{Al}_{2} \mathrm{O}_{3}\right)$ [10-11]. The properties of materials, ie mechanical, thermal and optical, directly influence the performances switches. From the above properties, the optical properties of materials used in the thermo-optical switches are very important. The microstructural properties of materials have a significant influence on the optical properties and there is a direct correlation between them. Even a small change in the microstructure of a material can have an important influence on its optical properties. For these reasons, theoretical modelling of optical properties is very complex. The optical properties determine how light will propagate when hits the input interface of material, in the volume of material, and at the output interface of material. The light propagation depends on the refractive index of the material. The refractive index of the material may be in the form of a real number or a complex number, depending on whether it is an absorbing or non-absorbing material. The imaginary part of the refractive index of the absorbing material is called the extinction coefficient.

If materials will be used for applications in optical communications, such as thermo-optical switches, it is appropriate that they have a minimum light absorption in the wavelength range for optical communications ( 850 $\mathrm{nm}, 1310 \mathrm{~nm}$ and $1550 \mathrm{~nm}$ ). Among the most common materials for the construction of thermo-optical switches belong $\mathrm{SiO}_{2}, \mathrm{Ta}_{2} \mathrm{O}_{5}$ and $\mathrm{Al}_{2} \mathrm{O}_{3}$. The optical properties of selected materials are investigated in the wavelength range around $1550 \mathrm{~nm}$, which is the wavelength used in optical communication over distances of more than $60 \mathrm{~km}$. From the optical properties are in this paper researched the reflectance, transmittance and influence of surface roughness on these parameters. These parameters are critical in light transmission and determine the amount of reflected (transmitted) light. Materials for thermo-optical switches should have minimum value of spectral reflectance and maximum value of light transmission in the relevant wavelength range. The reflectance and transmittance including surface roughness were in this paper simulated using the transfer matrix theory and modified Fresnel coefficient. Transfer matrix method is a numerical method that consists of multiplying two types of matrices. The first matrix is called refractive and the second matrix is called phase. The most general form of the refractive matrix and the phase matrix are defined by equation $[12-15]$

$$
\begin{aligned}
& \boldsymbol{R}_{i-1, i}=\frac{1}{t_{i-1, i}^{\mathrm{rgh}}}\left(\begin{array}{cc}
1 & -r_{i, i-1}^{\mathrm{rgh}} \\
r_{i, i-1}^{\mathrm{rgh}} & t_{i-1, i}^{\mathrm{rgh}} t_{i, i-1}^{\mathrm{rgh}}-r_{i-1, i}^{\mathrm{rgh}} r_{i, i-1}^{\mathrm{rgh}}
\end{array}\right), \\
& \boldsymbol{C}_{i}=\left(\begin{array}{cc}
\exp \left(i k n_{i} d_{i}\right) & o \\
0 & \exp \left(-i k n_{i} d_{i}\right)
\end{array}\right),
\end{aligned}
$$

where $k=2 \pi / \lambda, d_{i}$ is the thickness of $i$-th layer and $n_{i}$ is complex refractive index of $i$-th layer. The modified Fresnel coefficient $r$ describe light propagation in a multilayer planar stack with surface and intrastructure roughness considerations. The final form of transfer matrix of the multilayer structure is defined by equation, [13]

$$
\boldsymbol{N}=\boldsymbol{R}_{0,1} \prod_{i=1}^{m} \boldsymbol{C}_{i} \boldsymbol{R}_{i, i+1}
$$

where $m$ is number of layers. The modified Fresnel coefficients with roughness considerations are defined by equations, [13-15]

$$
\begin{array}{r}
t_{i, i-1}^{\mathrm{rgh}}=t_{i, i_{1}}^{\mathrm{o}} \exp \left[-\frac{1}{2}\left(\frac{2 \pi \sigma_{i}}{\lambda}\right)^{2}\left(n_{i-1}-n_{i}\right)^{2}\right], \\
r_{i, i-1}^{\mathrm{rgh}}=r_{i, i_{1}}^{\mathrm{o}} \exp \left[-2\left(\frac{2 \pi \sigma_{i} n_{i}}{\lambda}\right)^{2}\right], \\
t_{i-1, i}^{\mathrm{rgh}}=t_{i_{1}, i}^{\mathrm{o}} \exp \left[-\frac{1}{2}\left(\frac{2 \pi \sigma_{i}}{\lambda}\right)^{2}\left(n_{i}-n_{i-1}\right)^{2}\right], \\
r_{i-1, i}^{\mathrm{rgh}}=r_{i_{1}, i}^{\mathrm{o}} \exp \left[-2\left(\frac{2 \pi \sigma_{i} n_{i-1}}{\lambda}\right)^{2}\right],
\end{array}
$$

where $r$ and $t$ with index $o$ are standard Fresnel coefficients, $\sigma$ is interface roughness in $\mathrm{nm}$.

\subsection{Silica $\left(\mathrm{SiO}_{2}\right)$}

The main advantage of $\mathrm{SiO}_{2}$ is the stability of the refractive index and the possibility of its control. This material is also widely used in the production of optical fibers. $\mathrm{SiO}_{2}$-based single-mode waveguides exhibit low propagation and connection losses. Another advantage of $\mathrm{SiO}_{2}$ is its high transparency. The thermal dependence of the refractive index of $\mathrm{SiO}_{2}$ predetermines use of the $\mathrm{SiO}_{2}$-based single-mode waveguides in optical switches [10]. The refractive index of $\mathrm{SiO}_{2}$ used in simulations was described using the dispersion model, [16]

$$
N^{2}=A+\frac{B \lambda^{2}}{\lambda^{2}-C}+\frac{D \lambda^{2}}{\lambda^{2}-F},
$$




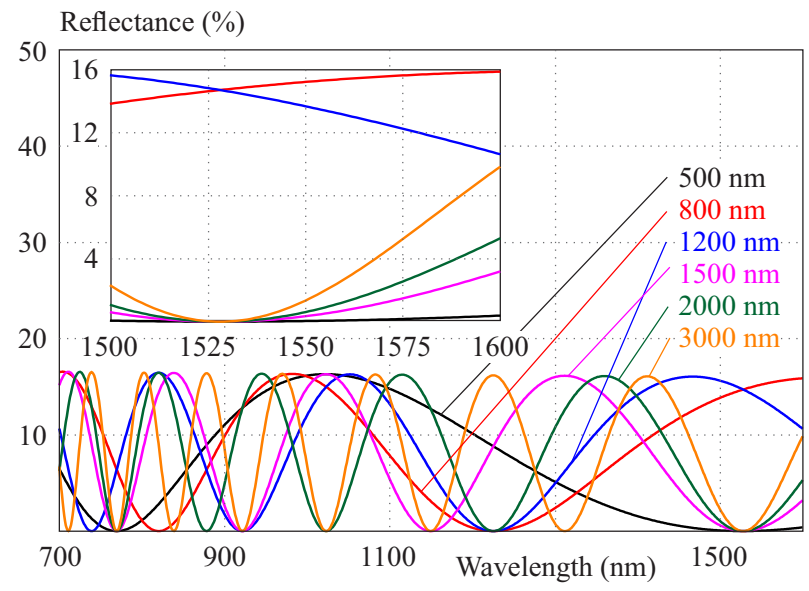

Fig. 3. Reflectance of $\mathrm{SiO}_{2}$ thin film with different thickness

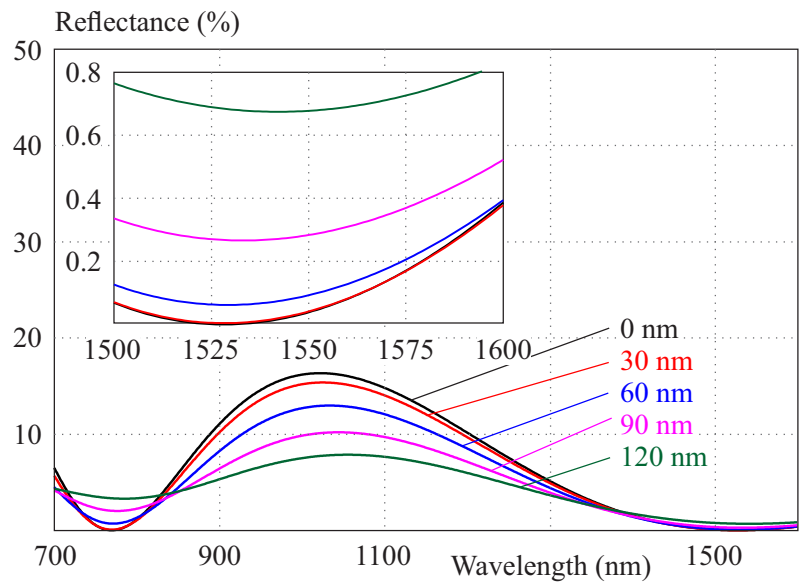

Fig. 5. Reflectance of $500 \mathrm{~nm} \mathrm{SiO}_{2}$ thin film with different surface roughness

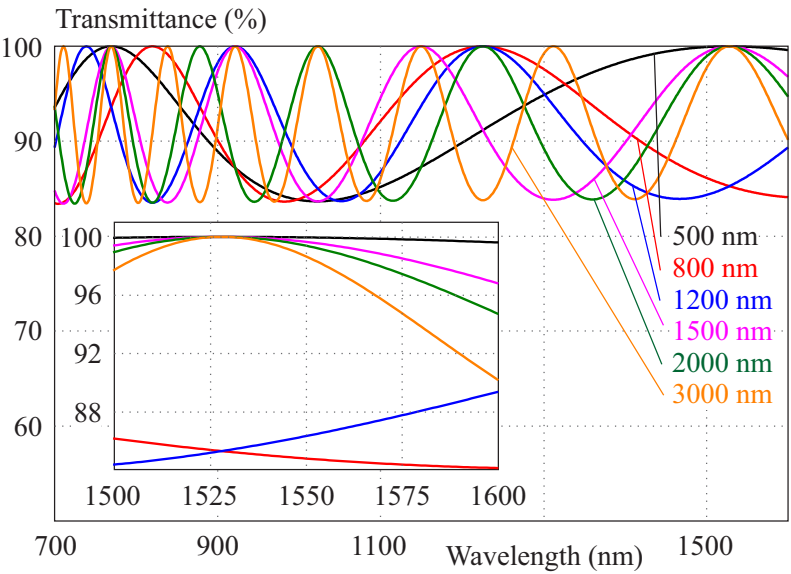

Fig. 4. Transmittance of SiOthin film with different thickness

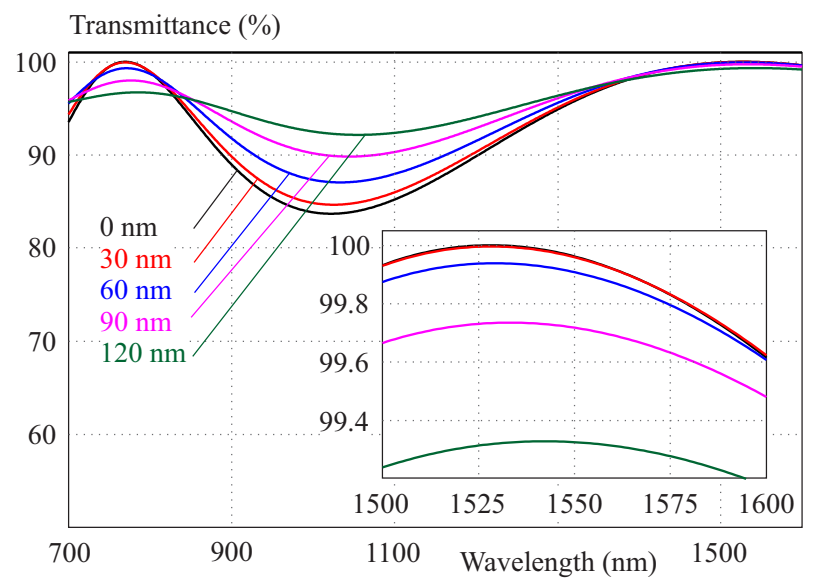

Fig. 6. Transmittance of $\mathrm{nm} \mathrm{SiO}$ thin film with different surface roughness

Table 2. Parameters of double Tauc-Lorentz oscillators dispersion model of $\mathrm{Ta}_{2} \mathrm{O}_{5}$

\begin{tabular}{cccccccc}
$\varepsilon_{\infty}$ & $E_{g}$ & $A_{1}$ & $A_{2}$ & $E_{1}$ & $E_{2}$ & $C_{1}$ & $C_{2}$ \\
\hline 1.380 & 4.105 & 191.567 & 62.619 & 4.996 & 6.350 & 4.002 & 0.711 \\
\hline
\end{tabular}

where $A, B, C$ and $D$ are the dispersion coefficients and coefficient $F$ represents the effective resonance absorption wavelengths in UV-IR region. The coefficients of the dispersion model of $\mathrm{SiO}_{2}$ used in presented simulations are listed in Tab. 1.

In Fig. 3-4 is shown reflectance and transmittance of $\mathrm{SiO}_{2}$ thin film with different thickness. The highest transmittance $(99.96 \%)$ in relevant wavelength for optical communication $(1550 \mathrm{~nm})$ is observed for $500 \mathrm{~nm}$ $\mathrm{SiO}_{2}$ thin film, while the $800 \mathrm{~nm} \mathrm{SiO}_{2}$ thin film shows the lowest transmittance $(84.77 \%)$. As can be seen in Fig. 5-6, in addition to the layer thickness, also the surface roughness has a significant influence on optical properties of $\mathrm{SiO}_{2}$ thin film, for this reason it is necessary to choose a suitable production process, which has a major impact on the quality of the structure. At the wavelength $1550 \mathrm{~nm}$, decrease in transmittance with increase in surface roughness is observed, it means, the roughness in this case has a negative effect on the optical properties of the $\mathrm{SiO}_{2}$ thin film, but this is not the case with the lower wavelength range (830 $1385 \mathrm{~nm})$, where an increase in surface roughness causes an increase in transmittance. The $500 \mathrm{~nm} \mathrm{SiO}_{2}$ thin film with a surface roughness of $120 \mathrm{~nm}$ showed a decrease in transmittance of $0.64 \%$ (at a wavelength of $1550 \mathrm{~nm}$ ) compared to the $\mathrm{SiO}_{2}$ thin film without surface roughness.

\subsection{Tantalum pentoxide $\left(\mathrm{Ta}_{2} \mathrm{O}_{5}\right)$}

$\mathrm{Ta}_{2} \mathrm{O}_{5}$ has promising potential to be one of the best optical coating materials because of its high index and low absorption, for near-UV and near-IR antireflection, multilayer filter design and optical thermometric sensing applications. $\mathrm{Ta}_{2} \mathrm{O}_{5}$ films can be deposited by various techniques such as chemical vapor deposition, electron beam evaporation, ion beam and dual-ion beam sputter- 


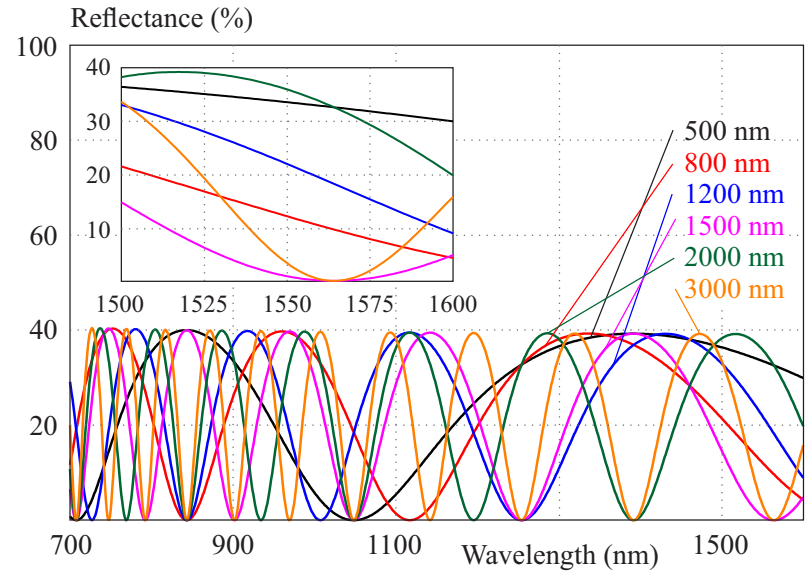

Fig. 7. Reflectance of $\mathrm{Ta}_{2} \mathrm{O}_{5}$ thin film with different thickness

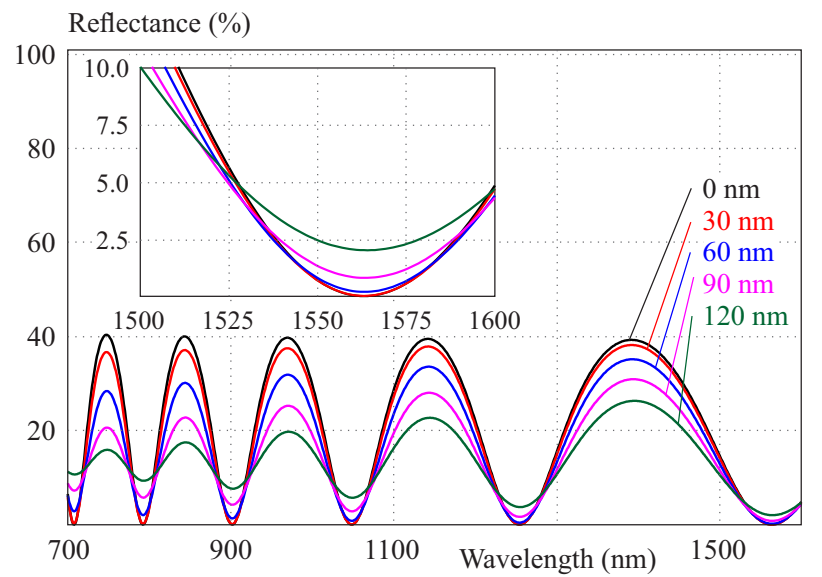

Fig. 9. Reflectance of $1500 \mathrm{~nm} \mathrm{Ta}_{2} \mathrm{O}_{5}$ thin film with different surface roughness

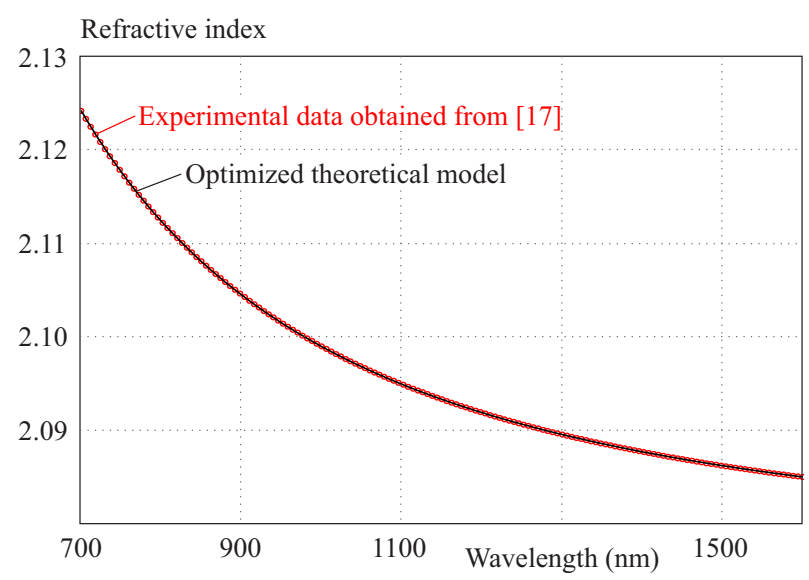

Fig. 11. Refractive index of $\mathrm{Ta}_{2} \mathrm{O}_{5}$ and optimized theoretical model

ing, reactive $\mathrm{RF}$ sputtering, DC sputtering, ion-assisted deposition and anode oxidation. Values of refractive index and extinction coefficient may vary depending on the fabrication technique used [10]. The numerical data of the refractive index used in simulations shown in Fig. 710 were taken from refractive index database of Mikhail Polyanskiy, these numerical data being obtained from experimental results published in [17]. The taken numerical

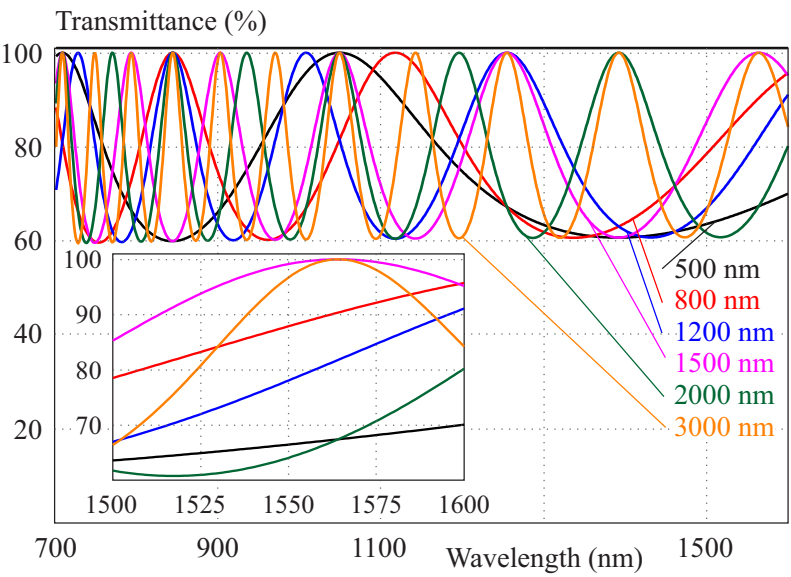

Fig. 8. Transmittance of taOthin film with different thickness

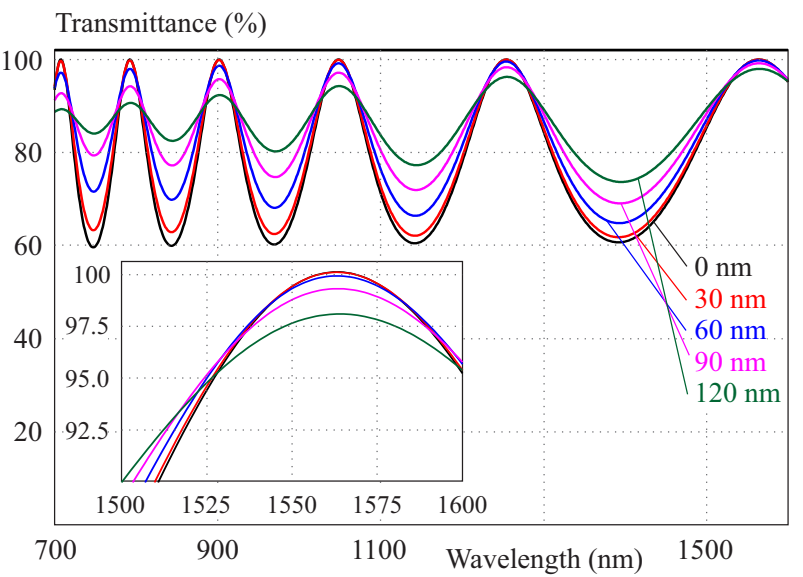

Fig. 10. Transmittance of $1500 \mathrm{~nm} \mathrm{Ta}_{2} \mathrm{O}_{5}$ thin film with different surface roughness

data of refractive index of $\mathrm{Ta}_{2} \mathrm{O}_{5}$ were optimized using Tauc-Lorentz dispersion model, [18]

$$
\begin{gathered}
\left.\varepsilon_{i}(E)=\frac{1}{E} \sum_{i=1}^{N} \frac{A_{i} E_{i} C_{i}\left(E-E_{g}\right)^{2}}{\left(E^{2}-E_{i}^{2}\right)^{2}+C_{i}^{2} E^{2}}\right), \\
\varepsilon_{r}(E)=\varepsilon_{r}(\infty)+\frac{2}{\pi} P \int_{E_{g}}^{\infty} \frac{\xi \varepsilon_{i}(\xi)}{\xi^{2}-E^{2}} \mathrm{~d} \xi,
\end{gathered}
$$

where indexes $r$ and $i$ represent real and imaginary part of complex dielectric function $\varepsilon, E_{g}$ is the optical band gap energy, $A_{i}, E_{i}, C_{i}$ all in $(\mathrm{eV})$ are treated as fitting parameters and $N$ is the number of oscillators. The optimized parameters of the two-oscillator $(N=2)$ TaucLorentz dispersion model of $\mathrm{Ta}_{2} \mathrm{O}_{5}$ are listed in Tab. 2 . Equation (5) is valid only for $E>E_{g}$ and for energies $E<E_{g}$ the result is zero. Equation (6) represents the Kramers-Kronig integral and the solution of this integral is given in [18].

In Fig. 7-8 is shown reflectance and transmittance of $\mathrm{Ta}_{2} \mathrm{O}_{5}$ thin film with different thickness. The highest value of transmittance $(99.16 \%)$ in relevant wavelength for optical communication $(1550 \mathrm{~nm})$ is observed with $1500 \mathrm{~nm} \mathrm{Ta}_{2} \mathrm{O}_{5}$ thin film. The lowest value of transmittance $(64.09 \%)$ at wavelength $1550 \mathrm{~nm}$ is observed with 


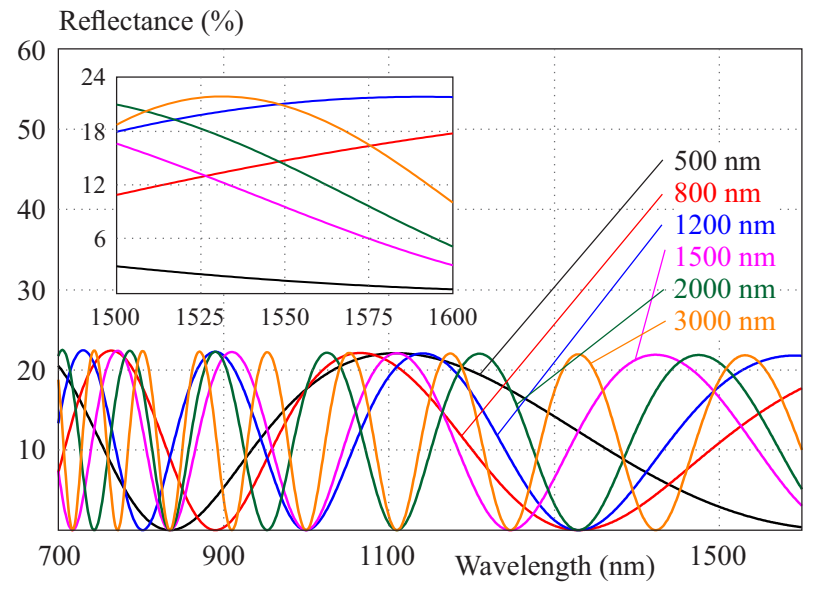

Fig. 12. Reflectance of $\mathrm{Al}_{2} \mathrm{O}_{3}$ thin film with different thickness

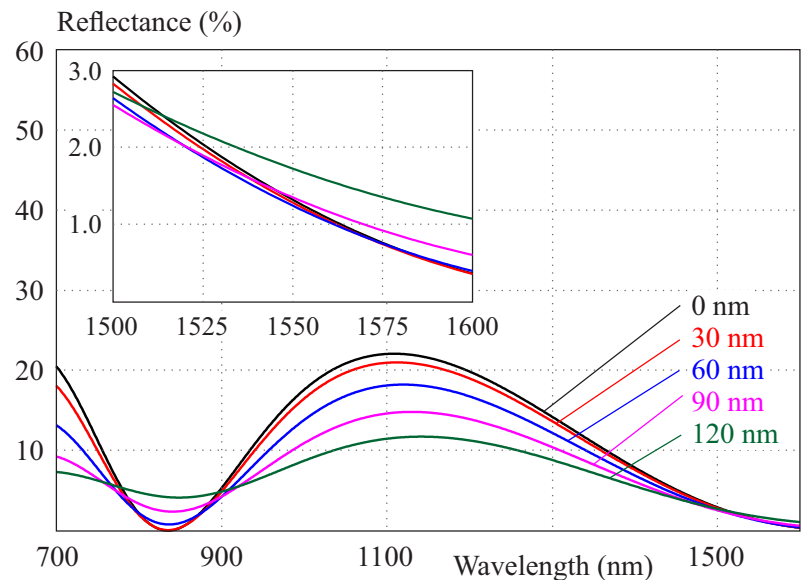

Fig. 14. Reflectance of $500 \mathrm{~nm} \mathrm{Al}_{2} \mathrm{O}_{3}$ thin film with different surface roughness

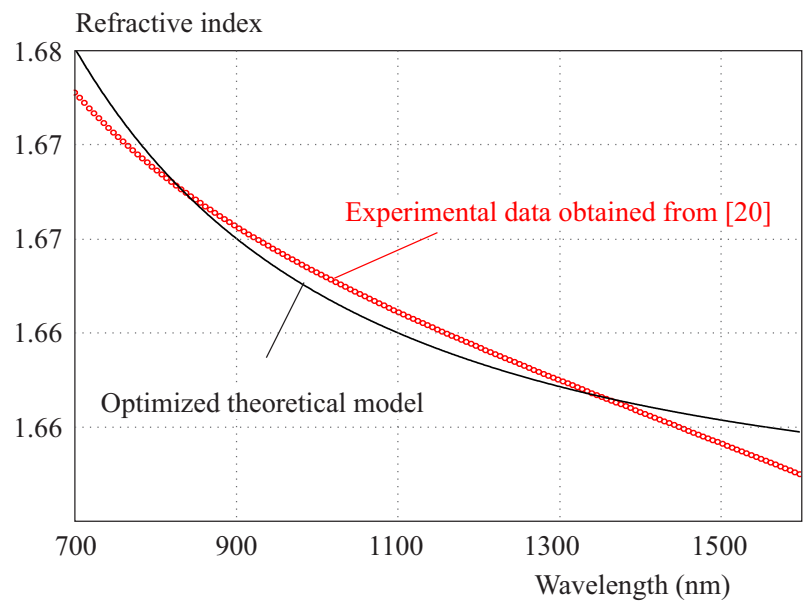

Fig. 16. Refractive index of $\mathrm{Al}_{2} \mathrm{O}_{3}$ and optimized theoretical model

$2000 \mathrm{~nm} \mathrm{Ta}_{2} \mathrm{O}_{5}$ thin film. As can be seen in Fig. 9-10 the transmittance of $\mathrm{Ta}_{2} \mathrm{O}_{5}$ thin film is also influenced by surface roughness. The $1500 \mathrm{~nm} \mathrm{Ta}_{2} \mathrm{O}_{5}$ thin film with a surface roughness of $120 \mathrm{~nm}$ showed a decrease in transmittance of $1.69 \%$ (at a wavelength of $1550 \mathrm{~nm}$ ) compared to the $\mathrm{Ta}_{2} \mathrm{O}_{5}$ thin film without surface roughness.

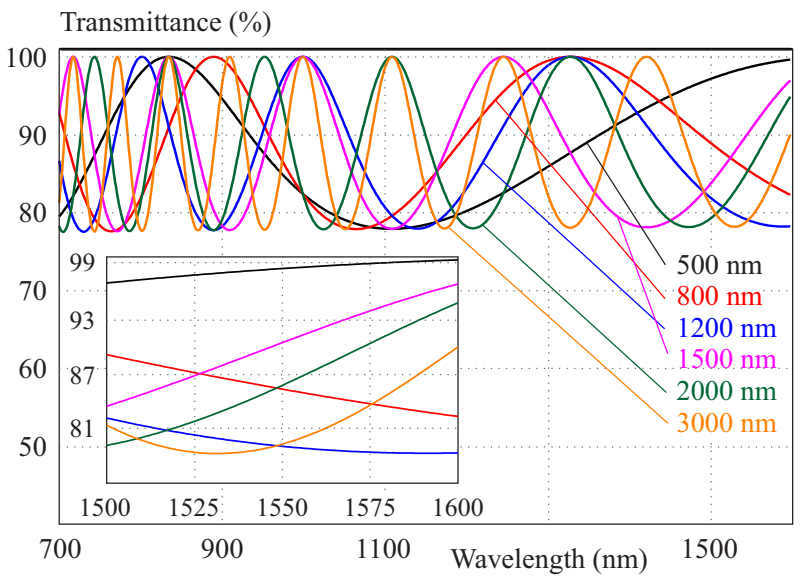

Fig. 13. Transmittance of alOthin film with different thickness

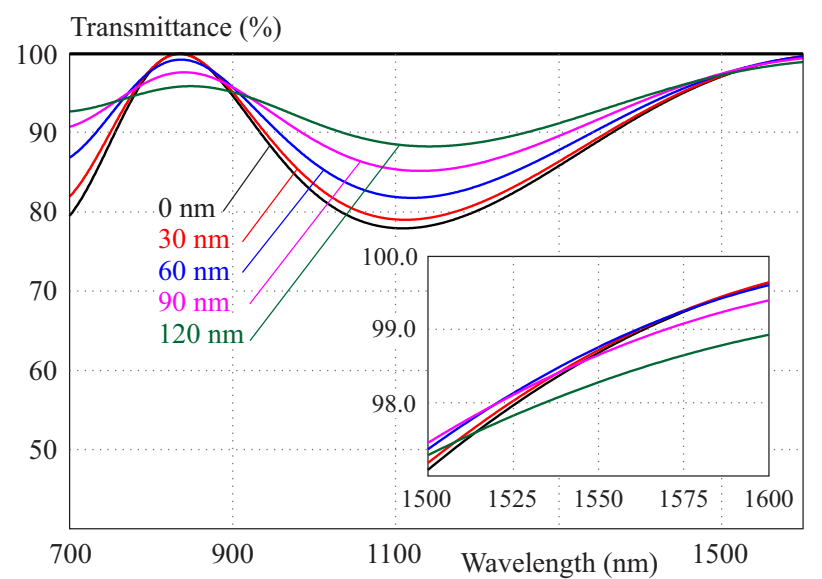

Fig. 15. Transmittance of $\mathrm{nm}$ alOthin film with different surface roughness

The surface roughness $(120 \mathrm{~nm})$ in the case of the 1500 $\mathrm{nm} \mathrm{Ta}_{2} \mathrm{O}_{5}$ thin film represented only $8 \%$ of the total layer thickness, however, the decrease in transmittance due to the surface roughness was most significant compared to the $\mathrm{SiO}_{2}$ and $\mathrm{Al}_{2} \mathrm{O}_{3}$ thin films.

In Fig. 11 are shown the experimental data of refractive index obtained from [17] and their optimized twooscillator Tauc-Lorentz dispersion model.

\subsection{Aluminium oxide $\left(\mathrm{Al}_{2} \mathrm{O}_{3}\right)$}

Very attractive material for thermo-optical switches is Aluminium oxide $\left(\mathrm{Al}_{2} \mathrm{O}_{3}\right)[10,11,19]$. The numerical data of the refractive index used in simulations shown in Fig. 12-15 were taken from refractive index database of Mikhail Polyanskiy, these numerical data were being obtained from experimental results published in [20]. These numerical data of refractive index of $\mathrm{Al}_{2} \mathrm{O}_{3}$ were optimized using single oscillator Lorentz dispersion model [21]

$$
\varepsilon(E)=\varepsilon_{\infty}+\sum_{i=1}^{N} \frac{A_{i}}{E_{i}^{2}-E^{2}-i E B_{i}},
$$

where $\varepsilon_{\infty}$ is the high frequency permittivity, $E$ is the energy, $A_{i}, E_{i}, B_{i}$ all in (eV) are treated as fitting parameters and $N$ is the number of oscillators. The optimized 
Blocking probability of data burts

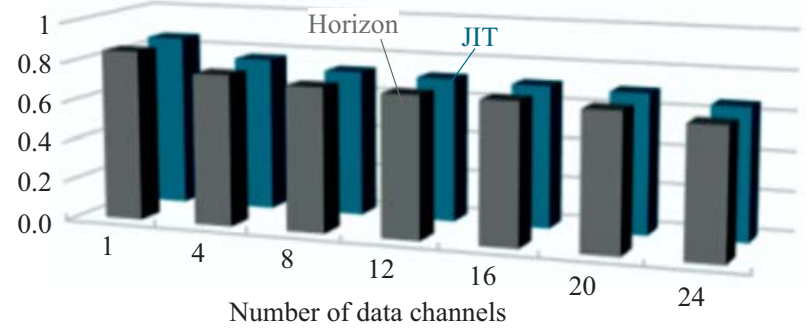

Fig. 17. Blocking probability of data bursts for JIT and Horizon reservation schemes with $\mathrm{SiO}_{2}$ thin film

parameters of the Lorentz dispersion model of $\mathrm{Al}_{2} \mathrm{O}_{3}$ are listed in Tab. 3.

Table 3. Parameters of the Lorentz dispersion model of $\mathrm{Al}_{2} \mathrm{O}_{3}$ in $(\mathrm{eV})$

\begin{tabular}{cccc}
$\varepsilon_{\infty}$ & $E_{1}$ & $A_{1}$ & $B_{1}$ \\
\hline 1 & 9.260 & 149.438 & 0 \\
\hline
\end{tabular}

Figure 12 and Fig. 13 show the simulations of reflectance and transmittance of $\mathrm{Al}_{2} \mathrm{O}_{3}$ thin films with different thicknesses. The highest transmittance at $1550 \mathrm{~nm}$ is observed by $500 \mathrm{~nm} \mathrm{Al}_{2} \mathrm{O}_{3}$ thin film ( $98.69 \%$ ). Significant decrease in transmittance at $1550 \mathrm{~nm}$ was observed for 1200 and $3000 \mathrm{~nm} \mathrm{Al}_{2} \mathrm{O}_{3}$ thin film ( $78.99 \%$ and 79.25 $\%)$. Fig-14-15 show simulations of the influence of surface roughness on the reflectance and transmittance of $500 \mathrm{~nm}$ $\mathrm{Al}_{2} \mathrm{O}_{3}$ thin film. As can be seen in Fig. 14-15, the influence of surface roughness on the spectral reflectance and transmittance of $\mathrm{Al}_{2} \mathrm{O}_{3}$ thin film was observed minimally compared to $\mathrm{SiO}_{2}$ and $\mathrm{Ta}_{2} \mathrm{O}_{5}$ thin films. The 500 $\mathrm{nm} \mathrm{Al}_{2} \mathrm{O}_{3}$ thin film with a surface roughness of $120 \mathrm{~nm}$ showed a decrease in transmittance of $0.41 \%$ compared to the $\mathrm{Al}_{2} \mathrm{O}_{3}$ thin film without surface roughness.

Figure 16 Shows the experimental data of refractive index obtained from and their optimized twooscillator tauclorentz dispersion model.

\section{The performance of thermo-optical switches}

Thermo-optical switches are very desirable due to their small size, large scalability and potentiality for short switching time. Therefore, the cross-connects in model of OBS network are used as core nodes with thermo-optical switching technologies. The model of OBS network is created using OMNeT ++ simulation environment. OBS network model is composed of two compound modules: edge nodes and core nodes interconnected by optical fibres. Two host modules and two edge nodes were set for each core node to generate as highest number of packets as possible and to create the highest amount of the bursts. The cross-connects are used as OBS core nodes with thermo-optical switching technologies. Reservation schemes JIT and Horizon are implemented in OBS network model. Because the main issue in OBS network is the random collision and burst loss, the blocking probability of data burst was expressed as the function of the number of data channels. As can be seen in Fig. 17, the blocking probability of data bursts decreases with increasing number of data channels and the performance of reservation schemes JIT and Horizon is very similar. The number of data channels in one optical fibre is shown in the range 1-24 because blocking probability of data bursts over 24 data channels was decreasing very slowly due to the heavy load of core node Core2. The switching time of each thermo-optical switch with $\mathrm{SiO}_{2}$ thin film was 5 (s [22]. As core nodes were used only thermo-optical switches with $\mathrm{SiO}_{2}$ thin film, because $\mathrm{SiO}_{2}$ is the most researched material for thermo-optical switches. $\mathrm{Al}_{2} \mathrm{O}_{3}$ a $\mathrm{Ta}_{2} \mathrm{O}_{5}$ are materials with high potential. The results also show that with shorter switching time of thermo-optical switches, the blocking probability of data bursts is lower and improves the throughput of OBS network.

\section{Conclusion}

In this paper were presented thermo-optical switches, the performance evaluation of thermo-optical switches executed in the model of OBS network and investigation of influence of roughness and layer thickness on the optical properties (spectral reflectance, transmittance) of selected materials for thermo-optical switches. The influence of parameters such as roughness and layer thickness on the optical properties of the studied materials was presented in order to show the importance of maintaining the accuracy of these parameters in the production process. Even a small deviation in these parameters can cause the optical switch to malfunction. Incorporating roughness into the optical model of selected materials was realized using the modified Fresnel coefficients. In terms of signal power transmission, the most important optical property of materials in thermo-optical switches is transmittance. Of the materials presented in this work, the $500 \mathrm{~nm} \mathrm{SiO}_{2}$ thin film has the best transmittance value $(99.96 \%$ ), followed by $1500 \mathrm{~nm} \mathrm{Ta}_{2} \mathrm{O}_{5}$ thin film with a transmittance of $99.16 \%$ and the $500 \mathrm{~nm} \mathrm{Al} \mathrm{O}_{3}$ thin film with a transmittance of $98.69 \%$ at the end. The influence of surface roughness was simulated for film thicknesses with the

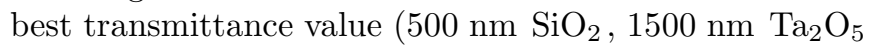
and $500 \mathrm{~nm} \mathrm{Al} \mathrm{Al}_{2} \mathrm{O}_{3}$ thin film). The most significant effect of surface roughness on transmittance was observed for $\mathrm{Ta}_{2} \mathrm{O}_{5}$ thin film, where at the surface roughness of $120 \mathrm{~nm}$ a decrease in transmittance of $1.69 \%$ was observed. With the same surface roughness, a decrease in transmittance of $0.64 \%$ was observed for $\mathrm{SiO}_{2}$ thin film and $0.41 \%$ for $\mathrm{Al}_{2} \mathrm{O}_{3}$ thin film. All transmittance values are given for the wavelength of $1550 \mathrm{~nm}$. The results presented in the part of the work dealing with simulation of OBS network model show that with shorter switching time of thermo-optical switches, the blocking probability 
of data bursts is lower and improves the throughput of OBS network. Therefore, the switching technology plays important role in the resource reservation and is very important for future optical networks. Optical switches based on thermo-optic effect are attractive candidates to realize high-speed all optical switching.

\section{Acknowledgements}

This work was partly supported by the Slovak Grant Agency under the projects VEGA 1/0840/18 and VEGA $1 / 0676 / 17$, by the Slovak Research and Development Agency under the projects APVV-17-0631, APVV-002512 and APVV-15-0152, by European Union's Horizon 2020 project no. 6260922 .

\section{REFERENCES}

[1] N. Amaya, S. Yan, M. Channegowda, B. R. Rofoee, Y. Shu, M. Rashidi, Y. Ou, E. Hugues-Salas, G. Zervas, R. Nejabati, D. Simeonidou, B. J. Puttnam, W. Klaus, J. Sakaguchi, T. Miyazawa, Y. Awaji, H. Harai, and N. Wada, "Software Defined Networking (SDN) over Space Division Multiplexing (SDM) Optical Networks: Features, Benefits and Experimental Demonstration", Optics Express, vol. 22, no. 3, pp. 3638-3647, 2014.

[2] P. J. Winzer, "Scaling Optical Fiber Networks: Challenges and Solutions", Optics \& Photonics News,vol. 26, no. 3, pp. 28-35, 2015.

[3] G. I. Papadimitriou, C. Papazoglou and A. S. Pomportsis, Optical switching Wiley, ISBN 978-0-471-68596-8, 2007.

[4] M. R. Umale, S. S. Jadhav, and S. D. Naravadkar, "Optical Burst Switching (OBS) for Next Generation Optical Transport Networks", International Journal of Computer Applications ETCSIT, vol. 1, no. 1, pp. 8-15, 2011.

[5] A. A. M. Saleh and J. M. Simmons, "All-Optical Networking-Evolution, Benefits, Challenges, and Future Vision", Proceedings of the IEEE, vol. 100, no. 5, pp. 1105-1117, 2012.

[6] J. Teng and G. N. Rouskas, "A Detailed Analyses and Performance Comparison of Wavelength Reservation Schemes for Optical Burst Switched Networks", Photonic Network Communications, vol. 9, no. 3, pp. 311-335, 2005.

[7] G. I. Papadimitriou, C. Papazoglou, and A. S. Pomportsis, "Optical Switching: Switch fabrics, Techniques and Architectures", Journal of Lightwave Technology, vol. 21, no. 2, pp. 384-405, 2003.

[8] S. Bregni, G. Guerra, and A. Pattavina, "State of the art of optical switching technology for all-optical networks", Communications World.
[9] K. Sakuma, H. Ogawa, D. Fujita, and H. Hosoya, "Polymer Y-branching thermo-optic switch for optical fiber communication systems", 8 th Microoptics Conference, pp. 24-26, 2001.

[10] B. Li and S. J. Chua, Optical Switches: Materials and Design, Woodhead Publishing, ISBN 9781845695798, 2010.

11] G. Coppola, L. Sirleto, I. Rendina, and M. Iodice, "Advance in thermo-optical switches: principles, materials, design and device structure", Optical Engineering, vol. 50, no. 7, 071112, 2011.

[12] S. J. Byrnes, Multilayer optical calculations Cornell University, arXiv:1603.02720v3, 2018.

13] C. L. Mitsas and D. I. Siapkas, "Generalized matrix method for analysis of coherent and incoherent reflectance and transmittance of multilayer structures with rough surfaces, interfaces, and finite substrates", Applied Optics, vol. 34, no. 10, pp. 1678-1683, 1995.

[14] C. C. Katsidis and D. I. Siapkas, "General transfer-matrix method for optical multilayer systems with coherent, partially coherent, and incoherent interference", Applied Optics, vol. 41, no. 19, pp. 3978-3987, 2002.

[15] C. F. Ramirez-Gutierrez, J. D. Castaño-Yepes, and M. E. Rodriguez-Garcia, "Porosity and roughness determination of porous silicon thin films by genetic algorithms", Optik, vol. 173, pp. 271-278, 2018.

16] G. Ghosh, "Dispersion-equation coefficients for the refractive index and birefringence of alcite and quartz crystals", Optics Communications, vol. 163, pp. 95-102, 1999.

[17] L. Gao, F. Lemarchand, and M. Lequime, "Exploitation of multiple incidences spectrometric measurements for thin film reverse engineering", Optics Express, vol. 20, no. 14, pp. 15734-15751, 2012.

[18] G. E. Jellison and F. A. Modine, "Parameterization of the optical functions of amorphous materials in the interband region", Applied Physics Letters, vol. 69, no. 3, pp. 371-373, 1996.

[19] S. Wiechmann and J. Müller, "Thermo-optic properties of $\mathrm{TiO}_{2}, \mathrm{Ta}_{2} \mathrm{O}_{5}$ and $\mathrm{Al}_{2} \mathrm{O}_{3}$ thin films for integrated optics on silicon", Thin Solid Films, 517, pp. 6847-6849, 2009.

20] R. Boidina, T. Halenkovič V. Nazabal, L. Beneš and P. Němec, "Pulsed laser deposited alumina thin films", Ceramics International, vol. 42, no. 1, pp. 1177-1182, 2016.

21] H. Fujiwara, Spectroscopic Ellipsometry: Principles and Applications Wiley, ISBN 978-0-470-01608-4, 2007.

[22] A. Densmore, S. Janz, R. Ma, J. H. Schmid, D. X. Xu, A. Delge, J. Lapointe, M. Vachon, and P. Cheben, "Compact and low power thermo-optic switch using folded silicon waveguides", Optics Express, vol. 17, no. 13, pp. 10457-10465, 2009.

Received 20 March 2021 